\title{
EQUILÍBRIO EM CENA: 0 QUE APRENDER COM AS PRÁTICAS ORGANIZACIONAIS DAS INDÚSTRIAS CULTURAIS
}

BALANGNACTE IEARNIGFROMORGANZNGPRACTICES INAUTRALINDUSIRES

\section{RESUMO}

N este artigo, delineamos cinco polaridades que envolvem as práticas organizacionais em indústrias culturais. Em primeiro lugar, os gestores devem reconciliar a expressão de valores artísticos com a viabilidade econômica do entretenimento de massa. Segundo, devem buscar inovações que diferenciem seus produtos sem torná-los fundamentalmente diferentes de outros da mesma categoria. Terceiro, devem analisar e atender a demanda existente e ao mesmo tempo usar a imaginação para expandir e transformar o mercado. Quarto, devem equilibrar as vantagens da integração vertical das diferentes atividades e a necessidade de manter uma vitalidade criativa por meio de especialização flexível. Finalmente, devem desenvolver sistemas criativos para apoiar e comercializar os bens culturais, mas não permitir que esses sistemas suprimam a inspiração individual que está na raiz da criação de valor na indústria cultural.

\section{Joseph Lampel}

Professor da Faculty of Management, Cass Business School - Londres, Inglaterra

J.Lampel@city.ac.uk

\section{Theresa Lant}

Professora do Management Department, Stern School of Business, New York University - Nova lorque, Estados Unidos

tlant@stern.nyu.edu

\section{Jamal Shamsie}

Professor do Department of Management, Broad Graduate School of Management, Michigan State University - Michigan, Estados Unidos shamsie@bus.msu.edu

Artigo Convidado. Aprovado em 13.11.2008.

Tradução de Caio Motta. Revisão Técnica de Thomaz Wood Jr.

Editor Científico: Rodrigo Bombonati

ABSTRACTIn this paper we outline five polarities that are shaping organizational practices in cultural industries. First, managers must reconcile expression of artistic values with the economics of mass entertainment. Second, they must seek novelty that differentiates their products without making them fundamentally different in nature from others in the same category. Third, they must analyze and address existing demand while at the same time using their imagination to extend and transform the market. Fourth, they must balance the advantages of vertically integrating diverse activities under one roof against the need to maintain creative vitality through flexible specialization. And finally, they must build creative systems to support and market cultural products but not allow the system to suppress individual inspiration, which is ultimately at the root of creating value in cultural industries.

PALAVRAS-CHAVE Bens culturais, arte, indústria do entretenimento, criatividade.

KEYMORS Cultural goods, art, entertainment industries, creativity. 
“... atual mentenos movemos rapidamente de uma era na qual os negócios eram a nossa cultura para uma era em que a cultura será o nosso negócio."

Marshall McLuhan

Cinema, televisão, música, teatro e artes visuais pertencem a uma categoria de produtos que se tornou conhecida como "bens culturais". Hirsch (1972, p. 641-642) define bens culturais como "bens 'não-materiais' direcionados a um público de consumidores para os quais geralmente têm uma função mais estética ou expressiva do queuma função utilitária". 0 atendimento dessas necessidades estéticas e expressivas produziu um setor econômico crescente cuja importância vai além de seu porte. As indústrias culturais são muito famosas, pois exercem uma influência extraordinária em nossos valores, nossas atitudes e nosso estilo de vida. Há muito tempo são objeto de intensa fascinação pública, uma fascinação nutrida e reforçada por uma forte cobertura de mídia.

No entanto, apesar de sua significância, a indústria cultural genericamente não tem recebido muita atenção dos pesquisadores de gestão. Há poucos estudos empíricos sobre essas indústrias, e ainda menos estudos que abordem as questões gerenciais e organizacionais que as empresas desses setores econômicos enfrentam. A explicação para essa omissão tem raiz na forma como os acadêmicos de gestão veem a indústria cultural. As práticas gerenciais e os padrões organizacionais tipicamente observados nessas empresas estão frequentemente em desacordo com as visões predominantes sobre o gerenciamento de organizações.

$\mathrm{Na}$ maioria das vezes, as tentativas de encaixar a indústria cultural nos quadros teóricos existentes são tolhidas por anomalias. Kuhn (1970) sugeriu que a primeira resposta a dar às anomalias é colocá-las de lado como meras curiosidades; depois, vêlas como interessantes, porém irrelevantes; e final mente, vêlas como interessantes e relevantes para o paradigma dominante. Entretanto, mesmo que as práticas gerenciais e organizacionais da indústria cultural até recentemente tenham sido consideradas anômalas, elas são cada vez mais difíceis de ignorar. Os gestores da indústria cultural aprendem a lidar com o conhecimento e a criatividade para intensificar o valor da experiência gerada por seus produtos. Os dilemas que eles encaram estão se tornando cada vez mais relevantes para um grupo cada vez maior de gestores em diversos contextos econômicos.

Muitas outras indústrias estão sendo atraídas por essa combinação entre conhecimento e criatividade para conseguir criar e sustentar vantagem competitiva. 0 conheci- mento, em particular o conhecimento técnico, étido como o fundamento da vantagem competitiva nos dias de hoje, mas conhecimento sem criatividade raramente pode dar conta do desafio da inovação contínua, necessária para sustentar a vantagem. Assim, como as empresas ligadas à indústria cultural têm lidado há muito tempo com esse desafio, sua experiência contém lições relevantes para outros setores econômicos.

Essas lições não estão reunidas em um conjunto de prescrições diretamente transferíveis, mas podem ser encontradas na maneira como as empresas da indústria cultural navegam entre imperativos opostos. Para entender a origem dessas polaridades, énecessário examinar a produção e o consumo de bens culturais de forma mais ampla. Fazemos isso na primeira parte deste texto. $\mathrm{Na}$ segunda parte, examinamos e discutimos as cinco polaridades intrínsecas à indústrias culturais. Utilizamos os artigos da edição especial de Organization Science (v. 11, n. 3, 2000) para organizar e ilustrar essas polaridades. Concluímos com implicações das lições extraídas das indústrias culturais para a gestão em outros setores econômicos.

\section{A COM PREENSÃO DAS INDÚSTRIAS CULTURAIS}

Para entender e distinguir o que é indústria cultural, é necessário apresentar sua característica principal: a natureza não-utilitária de seus bens. Na maioria das empresas desse tipo, é a utilidade que concede a definição das características dos produtos e seu uso. Mais especificamente, a utilidade permite a comparação sistemática de diferentes produtos, e dessa forma, fornece uma base para o surgimento de padrões de qualidade explícitos e relativamente estáveis.

Bens culturais, em contrapartida, são bens que geram experiências (BJORKERGREN, 1996; HIRSCH, 1972; HOLBROOK eHIRSCHMAN, 1982). Eles obtêm seu valor por meio das experiências subjetivas geradas, contando com o uso intensivo de símbolos para influenciar a percepção e a emoção. 0 impacto da música de fundo em determinadas partes de um filme mostra como mudanças sutis em produtos culturais podem alterar a experiência resultante. É óbvio que a imagem na tela deve dominar a experiência deum filme. No entanto, como os produtores de cinema e sua audiência bem sabem, a escolha da triIha sonora pode al terar fundamental mente a experiência resultante e, frequentemente, de uma maneira difícil de explicar ou prever.

A imprevisibilidade de tal experiência subjetiva torna extremamente difícil identificar e estabelecer clara- 
mente padrões de qualidade (BJORKERGREN, 1996; HOLBROOK e HIRSCHMAN, 1982; LEWIS, 1990; TUROW, 1984). Até mesmo quando há um amplo acordo sobre a alta (ou baixa) qualidade de produtos culturais, esse consenso oculta dissensos profundos sobre os motivos desse julgamento. Simples noções de qualidade tendem a se tornar contestáveis em indústrias culturais. Enquanto, em setores econômicos nos quais a importância dos bens é dada por sua utilidade, os produtores normal mente entram em consenso sobre padrões de qualidade específicos e muitas vezes mensuráveis, na indústria cultural os padrões representam ideais abstratos em vez de atributos específicos do produto. Por exemplo, os consumidores podem considerar que a "originalidade" é importante na arte ou na música, mas vincular significados profundamente distintos ao termo.

As opiniões sobre a qualidade do bem podem divergir tanto que os produtores consideram difícil entender por que al guns produtos se dão tão bem enquanto outros não. Isso não ocorre somente antes da decisão de compra, mas também depois. Em última instância, entender por que os produtos têm sucesso ou fracasso está sempre no domínio das conjecturas bem informadas. Isso raramente ocorre por falta de dados - normalmente há muitos dados disponíveis - mas porque os dados estão sujeitos a interpretações múltiplas e contraditórias. 0 conjunto dessas interpretações contraditórias cria ambiguidades que impactam a habilidade dos gestores para tomar decisões bem fundamentadas.

Quando tentam compreender os motivos pelos quais os consumidores de produtos culturais fazem as escol has quefazem, os gestores estão mais propensos a se sustentar em suas próprias percepções sobre a experiência subjetiva dos consumidores. 0 resultado está mais próximo de um processo de encadeamento interpretativo do que de uma análise sistemática ou racional. Por exemplo, os produtores de bens culturais sabem que os consumidores procuram produtos com que possam se entreter, estimular e refletir. Tentar satisfazer o consumidor nessas dimensões pode ser um enorme desafio.

No entanto, os produtores também sabem que os produtos culturais têm mais chance de sucesso no mercado quando misturam elementos familiares e inovadores. Os consumidores precisam de familiaridade para entender o que é oferecido, mas precisam de inovação para poder apreciar. Encontrar uma fórmula de sucesso com esses dois elementos opostos depende mais de arte do que de técnica, mais de percepção do que de discernimento profissional. As organizações que atuam na indústria cultural gastam muitos recursos procurando fórmulas para al can- çar esse objetivo, mas normalmente percebem como elas são ilusórias. Os gostos são instáveis, e, mais ainda, o que é inovador e famoso em um momento torna-se rapidamente familiar e antiquado.

É difícil encontrar especialistas na indústria cultural no sentido convencional do termo. Não há especialistas reconhecidos, como engenheiros ou analistas, que possam avaliar os produtos e apontar problemas quando el es surgem. 0 conhecimento codificado pode ser útil para lidar com problemas, mas, em última instância, tem um valor limitado. 0 conhecimento tácito é mais importante, e o talento, a criatividade e a inovação são os recursos cruciais para o sucesso (JONES e DEFILLIPI, 1996; MILLER e SHAM SIE, 1996). Entretanto, esses recursos são amorfos, isto é, não podem ser claramente definidos, surgem de fontes inesperadas, e perdem seu valor por motivos não total mente compreendidos.

Dessa forma, grande parte da estratégia das empresas da indústria cultural é orientada a encontrar, desenvolver e manter controle sobre esses recursos. Por exemplo, a maior parte das companhias possui departamentos de Artistas e Repertórios ( $A \& R$ ), cuja principal tarefa é encontrar edesenvolver novos artistas (WILSON, 1987). Os principais estúdios de Hollywood criaram sistemas para triagem e avaliação de milhares de novos scripts por ano para os poucos promissores que são produzidos (KENT, 1991). A editoras possuem departamentos cuja única tarefa é levar seus autores à atenção do público leitor pela orquestração de aparições públicas em conjunto com outros esforços de promoção e comercialização (COSER e outros, 1982).

Consequentemente, a sobrevivência a longo prazo na indústria cultural depende fortemente do reabastecimento de seus recursos criativos. No entanto, como há pouca compreensão sobre os processos que os geram, há uma incerteza considerável não só quanto ao modo de detectálos, mas também quanto à maneira de replicá-los e utilizáIos. Práticas gerenciais úteis em outras indústrias, como o treinamento dos profissionais, são pouco efetivas nas empresas da indústria cultural. Além disso, recursos comprovadamente valiosos estão normal mente incorporados a indivíduos e grupos sobre os quais a corporação tem controle limitado (STEARN S e outros, 1987; SAUNDRY, 1998; ROBINS, 1993).

0 gerenciamento de recursos criativos é, portanto, um dos desafios principais enfrentados pelas organizações na indústria cultural. Para lidar com esse desafio, tais organizações têm que recrutar e motivar pessoas que pareçam possuir a percepção e a intuição das formas de descobrir e nutrir recursos criativos. A vantagem competitiva depen- 
de da descoberta dessas pessoas e também do desenvolvimento de estruturas que alavanquem recursos criativos sem, ao mesmo tempo, sufocá-los.

Para recapitular nossos principais pontos, os produtores da indústria cultural enfrentam dois problemas: os padrões da demanda são imprevisíveis, e o monitoramento e controle do processo de produção é difícil. A evolução das empresas na indústria cultural ocorre pelas tentativas de lidar com esses problemas por mudanças constantes em práticas gerenciais e formas organizacionais. Do lado da demanda, as empresas tentam moldar as preferências do consumidor recorrendo a novos métodos de distribuição, comercialização e promoção. No entanto, moldar os gostos do consumidor é sempre difícil, e no caso da indústria cultural torna-se ainda mais difícil pelo fato de os gostos fazerem parte de uma matriz social e cultural mais ampla, sobre a qual as empresas têm pouco ou nenhum controle. Do lado da oferta, as empresas buscam desenvolver novas formas de descobrir e gerenciar inputs criativos. No entanto, a criatividade vem de pessoas cujo talento e cujos inputs só podem ser organizados e controlados até certo ponto. 0 gerenciamento bem-sucedido dos recursos criativos nas empresas da indústria cultural depende de se encontrar esse ponto, de estabelecer um equilíbrio entre os imperativos de liberdade criativa e os imperativos comerciais.

\section{NAVEGAÇÃO EM UM CONTEXTO CULTURAL}

Em seu exame da indústria cultural, Hirsch (1972) afirma que o surgimento de imperativos opostos é uma característica da indústria cultural em geral. Segundo ele, são sistemas de organizações que mediam o fluxo de bens entre produtores e consumidores. Para sobreviver, as organizações na indústria cultural devem reconciliar as demandas de produção artística com as demandas do mercado. Essas duas áreas não só possuem naturezas diferentes, mas normalmente estão em oposição - cada uma é moldada por necessidades diferentes, e cada uma é aval iada por diferentes critérios. As estratégias resultantes refletem as pressões opostas exercidas em cada extremo da cadeia de valor. Assim, para entender a indústria cultural, é importante entender as polaridades que moldam as escolhas disponíveis para as organizações nesses setores econômicos. N ossa leitura dos artigos da edição especial de Organization Science, mencionada anteriormente, sugere que há cinco polaridades que definem 0 campo de ação dentro do qual operam as organizações na indústria cultural.

\section{Valores artísticos versus entretenimento de massa}

As empresas da indústria cultural combinam dois domínios da experiência humana. Todas as sociedades produzem cultura como uma forma de expressão individual e coletiva de ideias e aspirações, porém o val or artístico dos produtos culturais deve ser equilibrado com seu val or de entretenimento. É por meio de seu valor de entretenimento que os produtos culturais atraem audiências que podem sustentá-los. A combinação desses dois domínios de arte e entretenimento é uma fonte de tensão contínua nas empresas da indústria cultural. Elas lutam para se manter leais a valores artísticos, mas também precisam lidar com a economia de mercado. Assim, a questão que persistentemente confronta as organizações na indústria cultural é: qual desses imperativos deve guiar a tomada de decisão? Os valores artísticos devem ser dominantes, deixando 0 entretenimento de massa em segundo plano, ou a organização deve usar a cultura para perseguir o objetivo do entretenimento?

Glynn (2000) aborda essa questão examinando a tensão entre os val ores artísticos e os imperativos comerciais em operação na Orquestra Sinfônica de Atlanta. De um lado, temos os membros da orquestra, comprometidos de forma passional com os ideais da música clássica, enquanto de outro, temos os membros do conselho, que desejam popularizar a música clássica e torná-la mais acessível ao público. A autora sugere que essa tensão não é facilmente resolvida. Quando o equilíbrio é estremecido por uma crise, cada um dos lados luta por seus próprios valores, inevitavelmente produzindo um conflito aberto entrearte e entretenimento. Em última instância, nenhum deles pode preval ecer sem destruir a identidade da organização. A coexistência é a única opção.

Enquanto no estudo de caso de Glynn (2000) a polarização entre arte e entretenimento é delineada de forma aguda, em muitas outras organizações o relacionamento é multidimensional e, portanto, mais complexo. No setor de teatro sem fins lucrativos, estudado por Voss e outros (2000), tanto há valores que competem entre si como valores que se sobrepõem. As organizações devem equilibrar e, quando possível, reconciliar esses val ores de acordo com o relacionamento com clientes-chave. A análise dos autores sugere que cinco valores distintos estão em jogo nesse setor. Há os valores artísticos dos próprios membros do teatro, os valores artísticos da comunidadee, além disso, o valor da reputação nacional da organização. Em conjunto com estes últimos, há também valores que são mais compatíveis com o sucesso comercial: o valor do desempenho financeiro, e o valor do sucesso no mercado, 
medido pela habilidade de sel ecionar peças que possuam apelo frente a uma audiência mais ampla.

\section{Diferenciação de produtos versusinovação de mercado}

A competição nas empresas da indústria cultural é guiada pela busca de inovação. No entanto, mesmo quando os consumidores esperam inovações em seus bens culturais, também querem que as inovações sejam acessíveis e familiares. Essa contradição coloca os produtores de bens culturais no meio de duas pressões opostas. De um lado, el es são impelidos a buscar inovações que diferenciem os produtos sem torná-los diferentes de outros da mesma categoria. Essa inovação representa a recombinação de elementos e estilos existentes que diferenciem os bens, mas que não rompam com as convenções artísticas e estéticas existentes. Por outro lado, há um impul so para perseguir a inovação al ém dos limites existentes. Esse tipo de inovação abre novos espaços, e frequentemente tem como decorrência novos tipos de produtos culturais, os quais podem expandir ou al terar fundamentalmente o mercado.

Mezias e M ezias (2000) examinam o equilíbrio entre a diferenciação de produtos e a inovação de mercado no início da indústria do cinema. Eles focam sua análise na criação de novos gêneros de cinema como eventos críticos de inovação. Novos gêneros representam novos tipos de produtos, mas ao mesmo tempo a inovação de um novo gênero é derivada de uma recombinação de estilos enarrativas existentes. A partir do atendimento de novos grupos de consumidores, o surgimento de cada novo gênero era esperado como uma expansão do mercado. No entanto, novos gêneros eram avaliados essencialmente pelos mesmos critérios utilizados para avaliar os já existentes. A criação denovos gêneros, como mostram Mezias e M ezias (2000), poderia ser entendida mais como uma forma de diferenciação de produtos do que uma forma de inovação de mercado.

0 artigo de Wijnberg e Gemser (2000) aborda essa tensão entre a diferenciação de produtos e a inovação em uma arena completamente distinta. Eles examinam a emergência da arte moderna, em particular o surgimento do Impressionismo na França na segunda metade do século XIX. Antes do Impressionismo, a arte era avaliada por meio de vários critérios, sendo que a inovação era apenas um deles. Os artistas buscavam diferenciar seu trabal ho dos de seus colegas, mas, ao mesmo tempo, buscavam manter uma continuidade em relação ao trabalho de seus predecessores. 0 Impressionismo realizou uma decisiva quebra das tradições e estilos estabelecidos nas artes visuais. Com isso, os impressionistas reconstruíram os fundamentos da arte moderna transformando o que era considerado inovador em um trabalho dentro dos critérios dominantes pelos quais seu valor era julgado.

\section{Análise da demanda versusconstrução do mercado}

Há uma antiga discussão na indústria cultural entre aqueles que veem os bens culturais como uma expressão de necessidades e desejos dos consumidores e os que argumentam que aquilo que os consumidores querem é quase inteiramente moldado pela imaginação e criatividade de seus produtores. Esse debate apresenta visões fundamentalmente distintas dos motivos pelos quais alguns bens culturais são bem-sucedidos enquanto outros fracassam. Temos então as seguintes posições: ou os bens culturais têm sucesso porque, deliberada ou acidentalmente, cobrem as preferências preexistentes dos consumidores; ou se tornam bem-sucedidos porque moldam os gostos para que se ajustem à sua própria produção - com efeito, eles criam os padrões pelos quais são julgados, e então propiciam uma experiência que atende esses padrões.

$\mathrm{Na}$ maioria das empresas da indústria cultural, longos períodos de estabilidade levam os gerentes a optar pelo primeiro caminho, ou seja, a tratar os bens culturais como bens sem nenhuma diferença em rel ação a outros tipos. 0 estudo de Anand e Peterson (2000) sobre as gravadoras de música demonstra os riscos envolvidos na utilização dessa premissa. Eles mostram que uma mudança na forma como a indústria coleta e anal isa as informações sobre os padrões de compra dos consumidores produz uma surpreen dente mudança na interpretação da estrutura do mercado. 0 que era percebido como uma imagem "objetiva" do mercado é revelado como um artefato dos métodos que a indústria utilizou para construir a imagem em primeiro lugar. 0 que 0 estudo de Anand e Peterson sugere é que o processo de leitura do mercado não pode ser sempre distinto dos processos que as empresas utilizam para construí-lo. Assim, o espelho direcionado ao mercado é feito pelas próprias empresas do setor. Portanto, como ele é desenhado com certas premissas em mente, a imagem resultante irá refletir tanto essas premissas quanto as preferências do consumidor.

0 artigo de Wijenberg e Gemser (2000) também versa sobre essa questão. É focado especificamente nos métodos que os produtores empregam para mudar os critérios utilizados para construir o mercado. Eles apontam para o fato de que os trabalhos artísticos não são avaliados independentemente do contexto no qual são produzidos, mas derivam seu val or a partir de um conjunto de instituições nas quais a arte é promovida e exibida. Essas instituições investem pesadamente em critérios que aumentem sua 
autoridade como "árbitros de gostos". Sua influência molda os processos nos quais os trabalhos artísticos são selecionados para a apresentação ao público ou fadados à obscuridade. Wijenberg e Gemser (2000) argumentam que o surgimento do Impressionismo reforçou uma transição, que já estava em andamento, do velho sistema de aval iação entre pares para um novo sistema de avaliação por especialistas. 0 principal ponto dessa transição foi a reavaliação da importância da inovação na arte. Com efeito, os impressionistas, em conluio com seus aliados, reformularam o gosto de seu público e também a forma como o mercado de arte lê o gosto dos consumidores. Sua revolução, portanto, não foi somente estética, mas também institucional.

\section{Integração vertical versusespecialização flexível}

$\mathrm{Na}$ indústria cultural, como também em muitos outros setores econômicos, as organizações normal mente buscam ganhos tentan do exercer maior controle sobre a criação e distribuição de seus produtos. Isso tem, invariavelmente, levado à integração de todos os aspectos da cadeia de valor sob um único "guarda-chuva" corporativo. N o entanto, a coordenação e os ganhos de escal a da integração têm que ser equilibrados com suas possíveis desvantagens. Uma empresa altamente integrada tende a reduzir a liberdade criativa de suas diferentes unidades para forçar uma maior coordenação. Assim, as empresas da indústria cultural precisam equilibrar essa necessidade de integração com al gumas tentativas de especial ização. $\mathrm{N}$ a medida em que uma empresa consegue se especializar, pode utilizar seu maior foco tanto para reduzir os custos gerais, corporativos, como para ampliar a flexibilidade criativa. A especialização permite que a organização se concentre nas atividades mais consistentes com seu papel específico na produção e distribuição de bens culturais, enquanto deixa 0 resto para outras organizações.

Em seu artigo sobre a indústria de cinema, Mezias e Mezias (2000) demonstram que as empresas podem conseguir grandes vantagens tanto por meio da integração como pela especial ização. Eles mostram que os produtores e distribuidores especializados têm maior probabilidade de criar gêneros do que os estúdios integrados, os quais constituem o núcleo da indústria. No entanto, os estúdios integrados se beneficiaram dessa prática porque a distribuição desses novos filmes permitia que el es expandissem seu mix de produtos. Mezias e Mezias (2000) sugerem, portanto, que, mesmo com o desequilíbrio entre riscos e retornos, os dois tipos de firmas desenvolveram uma relação simbiótica, isto é, mutuamente benéfica para ambos. De uma perspectiva ecológica, os movimentos inovadores das empresas especial izadas podem ser contrastados com os recursos dos estúdios integrados para aumentar suas chances de sucesso.

0 artigo de Starkey, Barnatt e Tempest (2000) lida com 0 equilíbrio entre emissoras integradas e fornecedores especializados na indústria de tel evisão do Reino Unido. Seu estudo mostra que, quando as emissoras se afastavam da integração total de produção e transmissão, começam a se sustentar em redes de especialistas externos. A flexibilidade fornecida por esses especial istas permitiu que as emissoras reduzissem os custos gerais sem impacto perceptível na qualidade dos programas. Isso foi alcançado pela criação daquilo queStarkey, Barnatt eTempest (2000) chamam de "organizações latentes". Elas representam estruturas sociais informais que podem permitir que uma emissora utilize especialistas externos para suprir suas necessidades de programação de forma intermitente. A virtude de tais estruturas latentes é que elas podem fornecer os meios pelos quais uma rede de especialistas que já trabalharam juntos antes possa utilizar seu alto grau de confiança e conhecimento mútuo para reconstituir eficientemente a rede.

\section{Inspiração individual versussistemas criativos}

Há um debate persistente na indústria cultural sobre a verdadeira fonte de valor criativo. É o indivíduo que é o elemento central na cadeia de valor ou é o sistema como um todo que produz os ingredientes críticos do sucesso de produtos culturais? Esse debate tem repercussões importantes. Se os indivíduos são os elementos centrais na criação de valor, então a chave para o sucesso é encontrar ou desenvolver esses indivíduos. Se, por outro lado, for o sistema, então deve ser dada menor ênfase aos indivíduos e maior no desenvolvimento de estruturas, processos e culturas que criem produtos culturais bem-sucedidos. Em muitas empresas da indústria cultural se podem encontrar tanto exemplos de organizações que colocaram sua confiança em indivíduos como organizações que colocaram sua confiança em sistemas. Com maior frequência, no entanto, as organizações tentam combinar o melhor de ambos.

0 estudo de Eisenmann e Bower (2000) sobre as empresas de mídia global mostra como o equilíbrio entre indivíduos e sistemas pode, sob certas condições, desfazer-se fortemente em direção aos indivíduos. Os autores argumentam que em ambientes nos quais tecnologia emercado rapidamente convergem, um sistema descentralizado de tomada de decisão é muito lento para identificar e tirar vantagem de oportunidades emergentes. As empresas de mídia que conseguem atingir economias de escal a e esco- 
po são normal mente dirigi das por presidentes com visão e ímpeto empreendedor. Esses executivos tomam decisões estratégi cas críticas, mas entregam as operações a unidades de negócios que possuem o conhecimento requerido para tirar vantagem de novas oportunidades. Dessa maneira, 0 crescimento e a integração são alcançados sem sacrifício da velocidade. Emerge daí um relacionamento que reforça mutuamente o executivo e o sistema, combinando a força da tomada de decisão centralizada com a coletiva.

0 artigo de Starkey, Barnatt e Tempest (2000) sobre a indústria de emissoras de tel evisão do Reino Unido ilustra como as empresas lidam com as tensões entre indivíduos e sistemas. No estudo, as emissoras se sustentam em um sistema de especial istas externos. A continuidade do sistema é sustentada por organizações latentes, mas estas se sustentam fortemente em agentes. A criatividade dos agentes e seu talento relacional são indispensáveis para ganhar projetos lucrativos, porém tais projetos são de difícil execução sem os talentos criativos presentes nas organizações latentes. 0 indivíduo e a rede, portanto, reforçam a posição um do outro, e é difícil separar a contribuição de cada um.

\section{CONCLUSÕES}

A indústria cultural é claramente diferente da mai oria das indústrias: seus produtos despertam experiências pessoais e ativam val ores e aspirações que não são nem utilitários nem comerciais. Em geral, eles se sustentam pelo uso bem-sucedido da criatividade, recurso que não pode ser controlado. Enquanto grande parte dessas características é própria da indústria cultural, ela lida com condições ambientais - em particular, al tos níveis de ambiguidadee dinamismo - cada vez mais comuns em outros setores.

Hirsch (1972) argumentou que os altos níveis de ambiguidade e dinamismo que existem na indústria cultural forçam os gestores a buscar constantemente novos modelos para gerenciar suas operações. Isso é bem semelhante ao que ocorre hoje em diversos outros setores econômicos. Os gerentes estão percebendo que al tos níveis de ambiguidade e dinamismo colocam regularmente em cheque as estruturas e práticas estabel ecidas. A incerteza persistente propicia o surgimento de discussão sobre os rumos futuros - discussão frequentemente estimulada pela premissa de que um paradigma dominante de negócio irá emergir assim que se reduzir o ritmo da mudança.

A indústria cultural tem vivido al to nível de dinamismo e ambiguidade por um longo período de tempo sem desenvolver paradigmas de negócio. Em vez disso, as or- ganizações na indústria cultural aprenderam a lidar com várias polaridades: valores artísticos ver sus entretenimento de massa, diferenciação de produtos versus inovação de mercado, análise de demanda ver sus construção de mercado, integração vertical versus especialização flexível, e inspiração individual versus sistemas criativos.

As polaridades normalmente propiciam o surgimento de debates, e este caso não é uma exceção. Para os pesquisadores, o debate é frequentemente um chamado para a ação, um incentivo a buscar evidências que apoiem um dos lados com o objetivo de refutar o outro. No entanto, devemos considerar que nenhum lado está completamente certo ou errado. Quando se lida com a prática do negócio de criação e venda de bens culturais, as empresas devem proceder com as polaridades em mente. Por exemplo, se as empresas têm como objetivo o entretenimento de massa, não devem perder de vista os valores culturais. Se os valores culturais dominam, a sobrevivência comercial exige que a realidade do mercado não seja ignorada indefinidamente. Se as empresas têm a intenção de criar novos gêneros ou novas categorias de bens culturais, devem ter em mente que a maioria dos produtos na indústria cultural têm sucesso pela diferenciação e não por serem revolucionários. Similarmente, se elas perseguem uma estratégia de diferenciação apenas marginal de seus produtos, devem estar cientes de que a longo prazo podem perder para estratégias que criem produtos verdadeiramente inovadores.

Com base na mesma lógica, as empresas devem analisar o mercado para entender como os consumidores provavelmente responderão, mas também devem tentar influenciar os consumidores encorajando o interesse em atributos nos quais seus produtos tenham vantagem. A anál ise cuidadosa do mercado garante que os produtores se comuniquem efetivamente com seus consumidores. Ao moldar o gosto, os produtores podem construir o mercado de forma a aumentar o valor de seus produtos.

Similarmente, novas tecnologias podem ajudar a transformar a especialização flexível em realidade, mas isso não elimina as vantagens da integração vertical. Grandes conglomerados de mídia podem estar aptos a alavancar a sinergia em suas unidades de negócios, mas se tentarem ir muito a fundo em tal busca, podem sufocar a criatividade da qual dependem.

Finalmente, quando observamos a última polaridade, inspiração individual versus sistemas criativos, encontramos um dos debates mais longos e difíceis da indústria cultural. A inspiração individual é defendida com frequência porque é mais fácil de identificar (mesmo que não seja tão fácil de enten dê-la), mas sem o apoio de um siste- 
ma criativo dificilmente será possível explorá-la de forma adequada. Os sistemas criativos frequentemente parecem ser mais confiáveis - e, portanto, são sempre uma forma tentadora de as empresas eliminarem sua dependência dos indivíduos criativos - mas, sem a inspiração de indivíduos criativos, o resultado com frequência degenera em uma pobre imitação dos sucessos do passado.

Conclui-se que buscar um equilíbrio entre as polaridades normal mente leva a uma combinação e extensão dos modelos existentes em vez do desenvolvimento de abordagens total mente inovadoras. Essa é, em última instância, uma lição crucial quea indústria cultural pode transmitir a outros setores que possuem condições ambientais similares, mas cujas polaridades em jogo são fundamentalmente distintas: as escolhas que as organizações enfrentam resultam de imperativos contrários. É importante entender como esses imperativos conflitam entre si. Com esse entendimento, elas podem decidir quais práticas devem ser modificadas e quais devem ser descartadas, quais formas organizacionais ainda são viáveis e quais devem ser abandonadas em favor de outras, completamente novas.

Artigo originalmente publicado por Joseph Lampel, Theresa Lant e Jamal Shamsie, sob o título Balancing Act: learning from organizing practices in cultural industries, na Organization Science, v. 11, n. 3, p. 263-269, 2000. Reproduzido em língua portuguesa com autorização dos autores e CINFORMS, 2008. O Institute for O perations Research and the Management Sciences, 7240 Parkway Drive, Suite 300, Hanover, Maryland 21076, USA. INFORMS não é responsável por erros na tradução do artigo original.

\section{REFERÊNCIAS}

ANAND, N; PETERSON, R. When market information constitutes fields: sensemaking of markets in the commercial music industry. Organization Science. v. 11, n. 3, p. 270-284, 2000.

BJORKGREN, D. The Culture Business. London: Routledge, 1996.

COSER, L. A; KADUSHIN, C. A; POW ELL, W. The Culture and Commerce of Publishing. Chicago: University of Chicago Press, 1982.

EISENMANN, T; BOWER, J. The entrepreneurial $m$-form: strategic integration in global media firms. Organization Science, v. 11, n. 3, p. 348-355, 2000.

GLYN N, M. When cymbals become symbols: conflict over organizational identity within a symphony orchestra. Organization Science, v. 11, n. 3, p. 285-298, 2000.

HIRSCH, P. Cultural industries revisited. Organization Science, v. 11, n. 3, p. 356-361, 2000.
HIRSCH, P. Processing fads and fashions: an organization-set analysis of cultural industry system. American Journal of Sociology, v. 77, n. 4, 1972.

HOLBROOK, M. B; HIRSCHMAN, E. C. The experiential aspects of consumption: consumer fantasies, feelings, and fun. Journal of Consumer Research, v. 9, n. 9, p. 132-140, 1982.

JONES, C, R; DEFILLIPI, J. Back to the future in film: combining industry and self-knowledge to meet the career challenges of the 21st century. Academy of Management Executive, v. 10, n. 4, p. 89-103, 1996.

KENT, N. Naked Hollywood. London: BBC Books, 1991.

KUHN, T. The Structure of Scientific Revolutions. Chicago: University of Chicago Press, 1970.

LEWIS, J. Art, Culture, and Enterprise. London: Routledge, 1990.

MEZIAS, J; MEZIAS, S. Resource partitioning, the founding of specialist firms, and innovation: the American feature film industry, 1912-1929. Organization Science, v. 11, n. 3, p. 306-322, 2000.

MILLER, D; SHAMSIE, J. The resource based view of the firm in two environments: the Hollywood film studios from 1936 to 1965. Academy of Management Journal, v. 39, p. 519-543, 1996.

ROBINS, J. A. Organization as strategy: restructuring production in the film industry. Strategic Management Journal, v. 14, p. 103-118, 1993.

SANDERSON, G; MACDONALD, F (Eds). MCLUHAN, M. The Man and H is M essage. Golden, CO: Fulcrum, 1989.

SAUNDRY, R. The limits of flexibility: the case of UK television. British Journal of Management, v. 9, p. 151-162, 1998.

STARKEY, K; BARNATT, C; TEM PEST, S. Beyond networks and hierarchies: latent organizations in the UK television industry. Organization Science, $\mathrm{V}$. 11, n. 3, p. 299-305, 2000.

STEARNS, T. M; HOFFMAN, A. N; HEIDE, J. B. Performance of commercial television stations as an outcome of interorganizational linkages and environmental conditions. Academy of Management Journal, v. 30, p. 71-90, 1987.

TUROW, J. M edia Industries. New York: Longman, 1984.

VOSS, G. e outros. Linking organizational values to relationships with external constituents: a study of non profit professional theatres. Organization Science, v. 11, n. 3, p. 330-347, 2000.

WIJNBERG, N; GEMSER, G. Adding value to innovation: Impressionism and the transformation of the selection system in visual arts. Organization Science, v. 11, n. 3, p. 323-329, 2000.

WILSON, M. How to Make it in the Rock Business. London: Columbus Books, 1987. 